\title{
Effect of Semen Freezing and Thawing on Sperm Survival and Motility Rate: A Comparative Analysis
}

\author{
Ram Dayal ${ }^{1 * 4}$, Sumer Singh ${ }^{2}$, Sunil K Thakur ${ }^{3}$, Prabhat Kumar ${ }^{2}$, Kamla Singh ${ }^{4}$, Pulakes Purkait ${ }^{3}$ \\ ${ }^{1}$ Department of Biotechnology, Singhania University, Pacheri Bari, Jhunjhunu, Rajasthan, India \\ ${ }^{2}$ School of Life Sciences, Singhania University,Pacheri Bari, Jhunjhunu, Rajasthan, India \\ ${ }^{3}$ Origin LIFE Healthcare Solutions and Research Centre LLP, Chandigarh, India \\ ${ }^{4}$ Institute of Reproduction and Child Cares and IVF Centre, Panchkula, Haryana, India
}

\begin{abstract}
Article Info

Volume 8, Issue 4

Page Number : 511-514

\section{Publication Issue}

July-August-2021

\section{Article History}

Accepted : 02 Aug 2021

Published : 12 Aug 2021

*Corresponding Author Ram Dayal ${ }^{*}, 4$, Ph.D. Sch.

${ }^{1}$ Dept. of Biotechnology, Singhania University, Jhunjhunu, Rajasthan, ${ }^{4}$ IRCC IVF Centre, Panchkula, Haryana, India

Objective: To compare the rate of sperm survival and motility through semen freezing and thawing during infertility treatment. Methodology: In this bidirectional observational study, we enrolled 31 patients who underwent semen analysis for infertility treatment at the Institute of Reproduction and Child Cares \& IRCC IVF Centre, Panchkula, Haryana, from June 2020 to December 2020. Out of these patients, 21 (67.74\%) were considered for semen freezing and thawing. For the rest of the ten patients (32.25\%), sperm count and motility were not good, and we excluded them from this study. Semen freezing based upon sperm count and motility were done. We did semen thawing after two weeks of semen freezing and recorded the sperm survival and motility. Results: Post thaw sperm survival rate and motility was $37.66 \%$ compare to precryopreservation (61.82\%). The observed rate of sperm motility declining was $24.16 \%$ after cryopreservation/freezing. Conclusion: The present study results concluded that sperm's cryopreservation results in a decrease in sperm motility. There is a need of finding more accurate and reliable methods to freeze and thaw semen.

Keywords: Semen Analysis, Semen Freezing, Freezing Media, Semen Thawing, Sperm Motility and Storage in Liquid Nitrogen.
\end{abstract}

\section{INTRODUCTION}

The cryopreservation or freezing of spermatozoa was introduced in the 1960s as a fertility preservation mechanism (1). Freezing of human semen is an essential procedure for fertility preservation of cancer patient and patients undergoing infertility treatment as a backup purpose. Even some fertile couples can experience difficulties in conceiving due to geographical or medical challenges. A general deterioration of male reproductive health over time is also an essential indication for sperm banking $(2,3)$. Intracytoplasmic sperm injection (ICSI) and in vitro fertilization (IVF) have completely advanced the 
male-factor infertility treatment. As a result, sperm freezing or cryopreservation has become a successful treatment option (4). Cryopreservation is a procedure where cells, tissues or other substances vulnerable to chemical damage over time are preserved by cooling at $-196^{\circ} \mathrm{C}$ temperature. In 1957 , the cryopreservation of tissues began with the freezing of fowl sperms (5). Cryopreservation was applied to humans in the mid1950s (6). In the present scenario, cryopreservation is the most valuable process used to preserve sperm in men undergoing gonadotoxic treatment such as radiotherapies or chemotherapies $(\mathbf{7}, \mathbf{8})$, which may lead to testicular failure or ejaculatory dysfunction. In addition to these, sperm cryopreservation is also offered in some non-malignant disorders, such as autoimmune diseases and diabetes (9), requiring treatments that may affect reproductive functions.

In the beginning, lowering the spermatozoa temperatures were observed by Lazaro Spallanzani in 1776(10). He observed that snow slowed the motions of sperms considerably, but sperms reached their previous motility when re-warmed.

Before 1949, many scientists recorded that sperm could survive freezing, but out of them, only a few could successfully fertilize the oocyte afterwards. In 1949, Polge et al. laid the foundation for cryopreservation of human sperm when they found a glycerol method to protect sperm injury during freezing. The first human pregnancy with frozen spermatozoa was successfully achieved in 1953 by Dr. Jerome K Sherman with other refined methodologies (11). Sperm motility, plasma membrane functionality, acrosome integrity and viability in post-thaw typically decrease in contrast to the pre-freeze state(12). Nijs et al. reported that the percentage of motile spermatozoa decreased from $50.6 \%$ to $30.3 \%$ after cryopreservation (13). The present study aims to determine the observational differences and carry out a comparative study of freezing and thawing semen regarding sperm survival and motility during infertility treatment.

\section{METHODOLOGY}

\section{Study design:}

This bidirectional study span was seven months (6months for laboratory work and 1-month for documentation and statistical analysis) from June 2020 to December 2020.

\section{Patients:}

A total of 31 Patients visited for semen analysis at the Institute of Reproduction and Child Cares \& IRCC IVF Centre, Panchkula, Haryana, were included in this study. Out of 31 patients undergoing semen analysis, 21(67.74 \%) were considered for semen freezing and thawing in this study. Twenty-one patients' sperm count and sperm motility before cryopreservation and two weeks of semen thawing were recorded (Table 1).

\section{METHODS}

All patients' routine semen analysis was done using the WHO manual of semen examination 2010(14). The patients with suitable sperm count and motility were enrolled in this study, and Semen freezing based upon sperm count and motility were done. We have used a single semen freezing protocol with a single semen freezing medium [FertiPro, Belgium] for all semen samples. We did semen thawing after two weeks of semen freezing and recorded the sperm survival and motility. The patients' data were categorized into two groups; pre cryopreservation data and post-thaw data. The consents of all the patients were taken for this study.

\section{INCLUSION CRITERIA:}

Patients with the following characteristics were included:

1. Patients with good sperm motility 
2. Patient with good sperm count

\section{EXCLUSION CRITERIA:}

The patients with severe oligozoospermia, azoospermia and necrozoospermia were excluded.

\section{SEMEN CRYOPRESERVATION:}

In a sterile container, the semen sample was collected and kept at $37^{\circ} \mathrm{C}$ for liquefaction. After liquefaction, the routine semen examination was done according to the world health organization' manual(14). Sperm concentration, motility and other parameters were recorded. Before use, $0.7 \mathrm{ml}$ of semen freezing medium was kept at $37^{\circ} \mathrm{C}$ to warming and equilibration. $1 \mathrm{ml}$ semen sample was cryopreserved by adding equilibrated semen freezing medium drop by drop within 10 minutes with continuous gentle shaking at $37^{\circ} \mathrm{C}$. This suspension was loaded into the pre-labeled cryovial, and vapor freezing was done using LN2 for at least 10 minutes. After 10 minutes, the vials were dipped in LN2 $\left(-196^{\circ} \mathrm{C}\right)$ and shifted in a proper canister till the thawing procedure. The details of the cryopreserved vial (location and storage) were recorded in the freezing record book.

\section{SEMEN THAWING:}

The cryopreserved vial was taken out from the cryocane of the LN2 storage cylinder and put at room temperature water for 5 minutes, and then kept in the incubator at $37^{\circ} \mathrm{C}$ for $30-60$ minutes for better sperm motility. Thawing is a rapid, manual, re-hydrating process executed with accuracy; otherwise, even an ideally frozen sample resulted in the feeble recovery of sperm post-thaw. After equilibration of the thawed sample, routine semen analysis was done. The sperm survival and motility were recorded.

\section{STATISTICAL ANALYSIS:}

Data analyses were done using the SPSS version 20 (IBM SPSS Statics for Windows, Version 20.0. Armonk, NY: IBM Corp.). T-test was employed to saw the difference between mean values in the two groups. $P<0.05$ was considered statistically significant.

\section{RESULTS}

In this pre cryopreservation and post-thaw sperm motility data of 21 patients (table 1), we analyzed those undergoing infertility treatments for seven months, June 2020 to December 2020. The respective average pre-cryopreservation and post-thawing sperm count was 108.66 million and 75.61 million. The average difference between these two was 33.04 million (30.40\%). Like sperm count, the average precryopreservation and post thawing sperm motility was $59.42 \%$ and $34.71 \%$, respectively. The average difference between Pre-cryopreservation and post thawing sperm motility was $24.71 \%$ which is depicted as a declining sperm motility rate after cryopreservation/freezing. This difference in sperm count and sperm motility values was significant (table 2) and showed an overall decline in these parameters of semen.

Table 1 : General characteristics

\begin{tabular}{|c|c|c|c|c|c|c|c|c|c|}
\hline \multirow[b]{2}{*}{$\begin{array}{c}\text { S. } \\
\text { no. }\end{array}$} & \multirow[b]{2}{*}{$\begin{array}{l}\text { Patient } \\
\text { ID }\end{array}$} & \multirow{2}{*}{$\begin{array}{c}\text { Semen } \\
\text { volume } \\
\text { in } \mathrm{ml}\end{array}$} & \multirow[b]{2}{*}{$\begin{array}{l}\text { CPAs } \\
\text { in } \mathrm{ml}\end{array}$} & \multicolumn{2}{|c|}{$\begin{array}{c}\text { Pre- } \\
\text { cryopreservation }\end{array}$} & \multicolumn{2}{|c|}{ Post thawing } & \multirow{2}{*}{$\begin{array}{c}\text { Difference } \\
\text { in pre and } \\
\text { post sperm } \\
\text { count }\end{array}$} & \multirow{2}{*}{$\begin{array}{c}\text { Difference } \\
\text { in pre and } \\
\text { post } \\
\text { motility } \%\end{array}$} \\
\hline & & & & $\begin{array}{l}\text { Sperm } \\
\text { count }\end{array}$ & $\begin{array}{c}\text { motility } \\
\text { type a+ } \\
\text { type b }\end{array}$ & $\begin{array}{l}\text { Sperm } \\
\text { count }\end{array}$ & $\begin{array}{l}\text { motility } \\
\text { type a+ } \\
\text { type b }\end{array}$ & & \\
\hline 1 & 0124 & $1.0 \mathrm{ml}$ & 0.7 & 95 & 88 & 66 & 45 & 29 & 43 \\
\hline 2 & 0125 & $1.0 \mathrm{ml}$ & 0.7 & 28 & 15 & 19 & 3 & 9 & 12 \\
\hline
\end{tabular}


Ram Dayal et al Int J Sci Res Sci \& Technol. July-August-2021, 8 (4) : 511-517

\begin{tabular}{|c|c|c|c|c|c|c|c|c|c|}
\hline 3 & 0126 & $1.0 \mathrm{ml}$ & 0.7 & 40 & 35 & 24 & 15 & 16 & 20 \\
\hline 4 & 0168 & $1.0 \mathrm{ml}$ & 0.7 & 200 & 95 & 140 & 55 & 60 & 40 \\
\hline 5 & 0176 & $1 \mathrm{ml}$ & 0.7 & 65 & 55 & 45 & 40 & 20 & 15 \\
\hline 6 & 0179 & $1 \mathrm{ml}$ & 0.7 & 160 & 65 & 112 & 45 & 48 & 20 \\
\hline 7 & 0178 & $1 \mathrm{ml}$ & 0.7 & 160 & 75 & 112 & 55 & 48 & 20 \\
\hline 8 & 0179 & $1 \mathrm{ml}$ & 0.7 & 110 & 55 & 77 & 45 & 33 & 10 \\
\hline 9 & 0185 & $1 \mathrm{ml}$ & 0.7 & 60 & 60 & 42 & 35 & 18 & 25 \\
\hline 10 & 0187 & $1 \mathrm{ml}$ & 0.7 & 26 & 20 & 18 & 3 & 8 & 17 \\
\hline 11 & 0190 & $1 \mathrm{ml}$ & 0.7 & 50 & 35 & 35 & 35 & 15 & 0 \\
\hline 12 & 0199 & $1 \mathrm{ml}$ & 0.7 & 220 & 55 & 154 & 35 & 66 & 20 \\
\hline 13 & 0238 & $1 \mathrm{ml}$ & 0.7 & 90 & 60 & 63 & 40 & 27 & 20 \\
\hline 14 & 0252 & $1 \mathrm{ml}$ & 0.7 & 162 & 58 & 113 & 45 & 49 & 13 \\
\hline 15 & 0253 & $1 \mathrm{ml}$ & 0.7 & 105 & 90 & 73 & 45 & 32 & 45 \\
\hline 16 & 0254 & $1 \mathrm{ml}$ & 0.7 & 180 & 95 & 126 & 75 & 54 & 20 \\
\hline 17 & 0256 & $1 \mathrm{ml}$ & 0.7 & 127 & 50 & 88 & 5 & 39 & 45 \\
\hline 18 & 0257 & $1 \mathrm{ml}$ & 0.7 & 70 & 65 & 49 & 30 & 21 & 35 \\
\hline 19 & 0258 & $1 \mathrm{ml}$ & 0.7 & 115 & 65 & 80 & 35 & 35 & 30 \\
\hline 20 & 0259 & $1 \mathrm{ml}$ & 0.7 & 124 & 67 & 86 & 16 & 38 & 51 \\
\hline 21 & 0260 & $1 \mathrm{ml}$ & 0.7 & 95 & 45 & 66 & 27 & 29 & 18 \\
\hline
\end{tabular}

Table 2 : t-test for difference in mean values in two groups

\begin{tabular}{|l|l|l|l|l|l|}
\hline Variables & Pre-cryopreservation & Post thawing & $\begin{array}{l}\text { Mean } \\
\text { difference }\end{array}$ & t-value & p-value \\
\hline Sperm count & $108.67 \pm 55.92$ & $75.62 \pm 39.44$ & $33.04 \pm 14.94$ & 2.213 & $\mathbf{0 . 0 3 3}^{*}$ \\
\hline $\begin{array}{l}\text { motility (type a+ } \\
\text { type b) }\end{array}$ & $59.43 \pm 22.08$ & $34.71 \pm 18.36$ & $24.71 \pm 6.26$ & 3.943 & $\mathbf{0 . 0 0 0}^{*}$ \\
\hline
\end{tabular}

\section{${ }^{*} \mathrm{p}$-value $<0.05$ is significant}

\section{DISCUSSION}

Cryopreservation of male gametes is a vital aspect of human fertility preservation. With the advancement in assisted reproductive technology, indication for sperm cryopreservation is expanding (Fakhrildin 2013). Sperm cryopreservation is a broadly used method to maintain and protect fertility during infertility and malignancy treatments (15). Further, sperm Cryopreservation epitomizes as the only preemptive measure for conserving fertility, enabling less infertile men to father their children (16).

In the present study, we have enrolled 31 patients for semen analysis during infertility treatment. Out of 31 , only 21 patients were found eligible to be included in this study for semen freezing and thawing. We observed a low sperm survival rate and motility post thawing, lower than sperm motility pre cryopreservation (61.82\%vs37.66\%). Similarly, there was a decline of $24.16 \%$ in sperm motility rate after cryopreservation/freezing. These results are in 
concordance with previous studies $(10,17,18)$. A study by Fakhrildin revealed a considerable, highly significant decrease in sperm parameters, including sperm concentration, sperm motility, progressive motility, and normal sperm morphology compared to pre-cryopreservation(17). Freeze-thawing caused a $37 \%$ reduction in typical morphological forms of sperm (18). The motility of sperms is found to decrease after cryopreservation (10). Sperm cryopreservation is a crucial factor of fertility management whose success determines the reproductive outcome of assisted reproduction technologies (ART). The use of suitable cryoprotectants and sperm selection technologies before and after cryopreservation seem to have the most significant impact on preventing DNA fragmentation, thus improving sperm cryo-survival rates (19). After cryopreservation/thaw, a significant decrease in sperm motility and viability was observed, along with sperm DNA fragmentation and DNA oxidative damage (20).

It was found that cryopreservation has deleterious effects on various parts of spermatozoa, especially on plasma lemma, acrosome and tail. Previous studies suggested several factors (like sudden temperature changes, ice formation and osmotic stress) during the cryopreservation that are reasons for poor sperm quality post-thaw (1). Post-thaw light microscopic studies revealed a considerable reduction in average spermatozoa viability rate (15). Age is also correlated with a deterioration of various semen parameters (volume, motility and morphology) except sperm concentration. A review by Kidd et al. reported a decrease in semen volume, sperm motility and normal sperm when a comparison was made among 30-yearold men and 50-year-old men (3). Cryopreservation has deleterious effects on various parts of spermatozoa, especially on plasma lemma, acrosomes and tails. Post-thaw light microscopic studies revealed a considerable reduction in average spermatozoa viability rate (15). Previous studies suggested several factors (like sudden temperature changes, ice formation and osmotic stress) during the cryopreservation that are reasons for poor sperm quality post-thaw (1).

However, cryopreservation should be offered to patients with several malignant or non-malignant diseases. A study found no statistically significant differences in sperm parameters when various diseased patients were studied. However, patients with diabetes showed poorer sperm counts (9). It was proposed that by simulating conditions similar to the in vivo conditions for the post-thaw semen samples. After thawing, waiting for some time is crucial to confirm the motility and count parameters of sperm before inseminating the samples. Blind insemination immediately after thawing should be avoided (10).

\section{CONCLUSION}

In summary, we found a considerable decline in sperm motility after cryopreservation and observed after thawing, sperm survival and motility was $37.66 \%$. In comparison to pre cryopreservation, sperm motility was $61.82 \%$. The reason for this may be the type of cryopreservents used. Age may be the other factor that can cause a reduction in semen parameters. Non-malignant diseases like diabetes can also be one of the reasons for the decline in semen parameters. However, cryopreservation should be offered to patients with several malignant or nonmalignant diseases and fertility preservation. Further studies are required to confirm the present findings in large sample size, along with the determination of underlying causes of decrease in semen parameters after cryopreservation and after the thaw.

\section{VII.ETHICAL ISSUE}

The independent institutional ethical committee approved this bidirectional observational study of semen freezing and thawing regarding sperm survival and motility of IRCC Hospital, Panchkula, Haryana, India. 


\section{CONFLICT OF INTEREST}

The authors declare no conflict of interest.

\section{ACKNOWLEDGEMENTS}

We would like to thank the members of the study populations, patients and control participants for voluntarily taking part in this research work and donating their samples and cooperation during data collection. We also thanks to the Director of IRCC hospital \& IVF centre for financial support.

\section{Authors Contributions:}

$\mathrm{RD}$ is responsible for designing the experiments; SS, PK associated with laboratory work; SKT responsible for the preparation of the manuscript; K.S. for clinical diagnosis of the patients; $\mathrm{PP}$ is responsible for preparation of the manuscript.

\section{REFERENCES}

[1]. Hezavehei M, Sharafi M, Kouchesfehani $H$, Henkel R, Agarwal A, Esmaeili Borzabadi V, et al. Sperm cryopreservation: A review on current molecular cryobiology and advanced approaches. Reproductive BioMedicine Online. 2018;37.

[2]. Jouannet P, Wang C, Eustache F, Kold-Jensen $\mathrm{T}$, Auger J. Semen quality and male reproductive health: the controversy about human sperm concentration decline. APMIS. 2001;109(S103):S48-S61.

[3]. Kidd SA, Eskenazi B, Wyrobek AJ. Effects of male age on semen quality and fertility: a review of the literature. Fertility and Sterility. 2001;75(2):237-48.

[4]. Gupta S, Sharma R, Agarwal A. The process of sperm cryopreservation, thawing and washing techniques. The Complete Guide to Male
Fertility Preservation: Springer; 2018. p. 183204.

[5]. Polge EJC. Low-temperature storage of mammalian spermatozoa. Proceedings of the Royal Society of London Series B-Biological Sciences. 1957;147(929):498-508.

[6]. Sztein JM, Takeo T, Nakagata N. History of cryobiology, with special emphasis in evolution of mouse sperm cryopreservation. Cryobiology. 2018;82:57-63.

[7]. Lass A, Akagbosu F, Abusheikha N, Hassouneh $\mathrm{M}$, Blayney M, Avery S, et al. A programme of semen cryopreservation for patients with malignant disease in a tertiary infertility centre: lessons from 8 years' experience. Human Reproduction. 1998;13(11):3256-61.

[8]. Trottmann M, Becker AJ, Stadler T, Straub J, Soljanik I, Schlenker B, et al. Semen Quality in Men with Malignant Diseases before and after Therapy and the Role of Cryopreservation. European Urology. 2007;52(2):355-67.

[9]. Ranganathan P, Mahran AM, Hallak J, Agarwal A. Sperm cryopreservation for men with nonmalignant, systemic diseases: a descriptive study. Journal of andrology. 2002;23(1):71-5.

[10]. Oberoi B, Kumar S, Talwar P. Study of human sperm motility post cryopreservation. Med J Armed Forces India. 2014;70(4):349-53.

[11]. Walters E, Benson J, Woods E, Critser J, editors. The history of sperm cryopreservation 2009.

[12]. Ozkavukcu S, Erdemli E, Isik A, Oztuna D, Karahuseyinoglu S. Effects of cryopreservation on sperm parameters and ultrastructural morphology of human spermatozoa. Journal of assisted reproduction and genetics. 2008;25(8):403-11.

[13]. Nijs M, Creemers E, Cox A, Janssen M, Vanheusden E, Castro-Sanchez Y, et al. Influence of freeze-thawing on hyaluronic acid binding of human spermatozoa. Reproductive biomedicine online. 2009;19(2):202-6. 
[14]. World Health O. WHO laboratory manual for the examination and processing of human semen. 2010.

[15]. Ozkavukcu S, Erdemli E, Isik A, Oztuna D, Karahuseyinoglu S. Effects of cryopreservation on sperm parameters and ultrastructural morphology of human spermatozoa. Journal of assisted reproduction and genetics. 2008;25:403-11.

[16]. Wang S, Wang Y, xu Y, Tang M, Fang J, Sun H, et al. Proteomic characteristics of human sperm cryopreservation. Proteomics. 2014;14.

[17]. Fakhrildin M-B. Effect of cryopreservation on some sperm parameters of infertile patients Iraqi Journal of Embryos and Infertility Researches. 2013;3(5):9-15.

[18]. O'Connell M, McClure N, Lewis S. The effect of cryopreservation on sperm morphology, motility and mitochondrial function. Human reproduction (Oxford, England). 2002;17:704-9.

[19]. Santo M, Tarozzi N, Nadalini M, Borini A. Human Sperm Cryopreservation: Update on Techniques, Effect on DNA Integrity, and Implications for ART. Advances in urology. 2012;2012:854837.

[20]. Zribi N, Feki N, Euch H, Gargouri J, Bahloul A, Ammar-Keskes L. Effects of cryopreservation on human sperm deoxyribonucleic acid integrity. Fertility and sterility. 2008;93:159-66.

\section{Cite this article as :}

Ram Dayal, Sumer Singh, Sunil K Thakur, Prabhat Kumar, Kamla Singh, Pulakes Purkait, "Effect of Semen Freezing and Thawing on Sperm Survival And Motility Rate : A Comparative Analysis", International Journal of Scientific Research in Science and Technology (IJSRST), Online ISSN : 2395-602X, Print ISSN : 2395-6011, Volume 8 Issue 4, pp. 511-517, July-August 2021. Available at doi : https://doi.org/10.32628/IJSRST218483 Journal URL : https://ijsrst.com/IJSRST218483 